\title{
The prosody of other-repetition in Italian: A system of tunes
}

\author{
G I O V A N N R O S I \\ University of California, Los Angeles, USA \\ University of Helsinki, Finland
}

\section{A B S T R A C T}

\begin{abstract}
As part of the project reported on in this special issue, the present study provides an overview of the types of action accomplished by other-repetition in Italian, with particular reference to the variety of the language spoken in the northeastern province of Trento. The analysis surveys actions within the domain of initiating repair, actions that extend beyond initiating repair, and actions that are alternative to initiating repair. Pitch contour emerges as a central design feature of other-repetition in Italian, with six nuclear contours associated with distinct types of action, sequential trajectories, and response patterns. The study also documents the interplay of pitch contour with other prosodic features (pitch span and register) and visible behavior (head nods, eyebrow movements). (Repetition, conversation, prosody, intonation, action, Italian)*
\end{abstract}

\section{N T R O D U C T I O N}

Repetition is a conversational phenomenon that has long fascinated students of language and social interaction. In and of itself, a repetition does little more than establish a link to something that has been said. And yet, this basic operation can have strikingly different pragmatic functions. How do speakers indicate what they are doing with repetition and how do recipients know what to respond with? In the project reported on in this special issue, we address these questions by analyzing sequences of conversation in which a speaker repeats all or part of what another has said so as to problematize or otherwise engage with it, typically soliciting a response (see Rossi, introduction, this issue). The project focuses particularly on the role of prosody in the design and understanding of other-repetition, and does so across five languages.

One of the findings of the project as a whole is that other-repetition is used to accomplish certain recurrent types of action that are common across languages (e.g. seeking confirmation, questioning acceptability, registering), many of which have been identified in previous literature (see Rossi, introduction, this issue). These types of action can be seen as generic functions that emerge out of the complex social-interactional contingencies, particulars, and nuances that other-repetitions are enmeshed in.

The present study reports findings on the Italian language, specifically on the variety spoken in the northeastern province of Trento. The study surveys a range 
of different actions accomplished by other-repetition, actions that are reflected in the sequential development of interaction and in the responses that are made relevant or afforded by the repetition. It shows that pitch contour is a central element in this process and suggests that speakers of Italian rely on a system of tunes to design repetitions and ascribe import to them. The analysis also documents the interplay of pitch contour with other prosodic features of repetitions (pitch span and register) and with elements of visible behavior (head nods, eyebrow movements).

In what follows, I first provide some background on the Italian language and on the study of intonation and pragmatic function. I then present my data and method, and illustrate the basic structure of other-repetition sequences. The analytic sections follow the common structure adopted in the articles in the special issue, starting from actions of initiating repair, moving then to actions that extend beyond initiating repair, and ending with actions other than initiating repair. I conclude by discussing the results of the study and its implications for our understanding of action formation and ascription, and for the question of the meaning of intonation and prosody.

\section{B A C K G R O U N D}

\section{The Italian language}

Italian is a Romance language spoken by over sixty million people in Italy, Southern Switzerland, and by migrant communities in several other countries, the largest of which are found in the United States, France, and Canada (Lewis, Simons, \& Fennig 2014). The Italian language is characterized by a profusion of geographical variation. In Italian dialectology, the Italian Peninsula is typically divided into six main areas: Northern, Venetian, Tuscan, Central, Southern, and Extreme Southern. But variation is significant even within these areas, particularly in the domain of intonation (Bertinetto \& Loporcaro 2005; Krämer 2009; Gili Fivela et al. 2015). The present study focuses on a specific variety spoken in the northeastern province of Trento, which belongs to the Venetian area.

A general feature of the Italian language that is of interest for the present study is that there are generally speaking no morphosyntactic means for distinguishing polar (yes/no) interrogatives from declaratives. While it is commonly held that intonation compensates for this (e.g. Gili Fivela et al. 2015), interactional research suggests caution in claiming straightforward mappings between intonation and polar questions (Rossano 2010). Since other-repetitions often work as polar questions, examining the use of intonation in this context gives us an opportunity to probe its role in distinguishing pragmatic functions.

\section{Italian intonation and pragmatic function}

There is by now a large body of literature on the intonation of Italian and its varieties (see Grice, D’Imperio, Savino, \& Avesani 2005; Gili Fivela et al. 2015, for reviews). While adopting the autosegmental-metrical framework, recent studies 
describe intonational inventories with reference to nuclear contours, consistently with the British tradition (see Rossi, introduction, this issue). Nuclear contours or configurations are combinations of the last or primary pitch accent and one or more of the following boundary tones. Put another way, nuclear contours comprise the section of an utterance that goes from the last main pitch 'landmark' (Nolan 2006:436) through to its end.

This literature documents the extensive variation of intonation systems across the Italian Peninsula, in terms of tonal inventory, structure, and alignment. At the same time, its goal is to establish mappings between intonation and pragmatic functions. The largest study to date (Gili Fivela et al. 2015) offers a survey of nuclear contours for statements, polar questions, $w h$-questions, imperatives, exclamatives, and vocatives as part a major project to document the intonation-pragmatics interface across Romance languages (Frota \& Prieto 2015). The study also examines further distinctions between subtypes of polar questions, including information-seeking, confirmation-seeking, and echo questions, the latter of which subsume what we refer to here as other-repetitions.

This literature has accumulated a wealth of knowledge on the intonational structure and repertoire of Italian varieties. At the same time, its analysis of the relation between intonation and pragmatic function is limited by a methodology that is still largely based on read or elicited speech. This leaves open the question of how the proposed mappings relate to distinctions found in natural conversation.

A few studies in the field of intonational phonology are based on more spontaneous speech produced in experimental, task-oriented dialogs (e.g. Grice \& Savino 2003). This approach adds a significant degree of ecological validity to the analysis, which is framed in terms of 'conversational moves', including initiating and responding moves, and types of moves such as 'queries', 'checks', 'objections', and 'acknowledgements'. At the same time, the identification of these moves and more generally of pragmatic categories is based primarily on information status (given, new, accessible) and on the speaker's degree of confidence about it. This information-centered approach limits the reach of these studies into the range of meanings and functions that intonation serves in social interaction.

The present study, and the larger project of which it is part, adopts the framework of conversation analysis (see Rossi, introduction, this issue), where pragmatic function is approached in terms of social action. In conversation analysis, pragmatic distinctions are induced from the sequential development of interaction and from the responsive behavior of participants, and the attribution of meaning is grounded in observable details of talk and other conduct that exhibit the participants' own understanding of each other's actions.

\section{A T A A N D E T H O D}

The data for this study come from a large corpus of video recordings of naturally occurring face-to-face interaction among speakers of Italian living in the province of Trento in northeast Italy. Like in other areas of Italy, speakers in this province 
may alternate or mix Italian with the local Romance vernacular, Trentino (see extracts (6) and (9)). Regional Italian and vernacular are often inextricably interwoven in the speech of Italian speakers and both are integral parts of local Italian culture. Participants in the recordings are family, friends, neighbors, or otherwise people who know each other well, engaging in a broad range of activities from gossiping to playing games to doing household chores to eating together.

The study is based on a sample of twenty-two recordings from the corpus for a total of eleven hours. For each recording, I identified all cases of other-repetition in a continuous stretch of interaction until I either reached fifteen cases (to avoid oversampling) or exhausted all cases in the recording. The sample so constructed yielded 158 other-repetition sequences.

The conceptual and methodological framework adopted in the study, and in the larger project of which it is part, is explained in detail in the introduction to the special issue. Here I add a few notes on transcription and on the presentation of acoustic data.

Prosodic features are transcribed according to GAT 2 conventions (CouperKuhlen \& Barth-Weingarten 2011). These include symbols for indicating pitch movement on accented syllables and at the end of the utterance (e.g. una $r^{i^{\wedge}}$ STAM$p a$;). Such features are marked for all repetition turns and for other relevant turns. Some extracts also include representation of visible behavior following Mondada's (2019) conventions for multimodal transcription.

Visual representations of acoustic data were produced using the Praat software (Boersma \& Weenink 2020) and a script created by Gareth Walker. ${ }^{1}$ In each figure, pitch is plotted on a logarithmic Hertz scale to better represent the nonlinear perception of pitch, and the top and bottom of the pitch panel correspond to the speaker's range, which was calculated on the basis of approximately three minutes of speech. The calculation also included the speaker's median pitch, which is indicated by a horizontal dashed line in each figure.

\section{S TR UCT URE OF OTHER-REPETITION} S E Q UEN C ES

Other-repetition sequences have a three-part structure that is analogous to that of other-initiated repair (Schegloff, Jefferson, \& Sacks 1977; Dingemanse \& Enfield 2015). In the original turn, a speaker says something; in the repetition turn, another speaker repeats all or part of what the first speaker has said; in the response turn, the speaker of the original saying responds to the repetition, for example, by confirming what they have said.

In (1) below, Ettore and Sofia are preparing for a dinner party at their home. When the extract begins, Ettore is counting up how many people there are going to be for dinner (line 1), then announcing 'we are six' (line 3). This announcement comes in overlap with another announcement by Sofia about what she is going to do with one of the pots on the stove (line 2). After a silence, Sofia repeats what Ettore 
has said ('we are six'), which he then confirms ('yes'). The development of the sequence suggests that Sofia repeats Ettore's announcement to check that she has heard or understood it correctly.

(1) (BrentoPrep_322341)

1 Ettore: $\quad<<\mathrm{p}>$ uno [due, $>$

2 Sofia: [allora questa la [tolgo adesso

'then I'll remove this one now'

3 Ettore: [in `SEi siamo. ORIGINAL TURN

'we are six'

in six be.1PL

(1.2)/((Sofia continues stirring soup))

5 Sofia: $\begin{array}{ll}\text { in }{ }^{\wedge} \mathrm{SEi} \text { siamo. } & \text { REPETITION TURN } \\ & \text { in six be.1PL }\end{array}$

6 Ettore: sì. $\quad$ RESPONSE TURN

$7 \quad(7.7) /(($ Sofia continues stirring soup,

Ettore begins to unload drying rack))

This example shows that the phenomenon of other-repetition overlaps with the domain of other-initiated repair. Other-repetition, however, is formally narrower and functionally wider than other-initiated repair. The criteria for delimiting the phenomenon formally are detailed in the introduction to the special issue. As for function, the following sections illustrate how other-repetition is used to accomplish actions of initiating repair, actions that extend beyond initiating repair, and actions other than initiating repair.

\section{N I T I A T I N G R E P A I R}

As seen in the previous section, repeating what another speaker has just said can be a way to initiate repair of it. An action of initiating repair suspends the progress of conversation to deal with a problem of hearing or understanding, which needs to be solved in order for progress to resume. As a practice for initiating repair, otherrepetition displays a certain degree of access to the preceding talk and thus helps to locate and identify where and what the trouble is (Schegloff et al. 1977:369). While narrowing the problem down, however, a repetition in and of itself does not specify what kind of repair operation may be required to solve the problem. In this section, I show that, in Italian, the pitch contour with which the repetition is produced serves to distinguish between two alternative operations that are recurrently sought to solve a problem of hearing or understanding: completion and confirmation. 


\section{Seeking completion}

When seeking completion, a repetition speaker requests that the previous speaker reiterate or reproduce a segment of the preceding talk that was not (fully) heard or understood. The term completion captures the particular way in which this repair operation is prompted: the speaker initiating repair repeats the preceding talk up to and excluding the problematic segment in order to 'frame' it (Jefferson 1972:296; see also Dingemanse, Blythe, \& Dirksmeyer 2014; Persson 2017, and references therein), which makes relevant the provision of the missing segment.

In (2), Sara and Furio are cracking and shelling walnuts to make cookies. When the extract begins, Furio is listing some of the other things they should do next ('like weighing the flour', line 1), to which Sara responds by stating that their first order of business should be the 'challenge of the kernels of walnut' (lines 3-4). ${ }^{2}$ In overlap with the last part of her turn (di noce 'of walnut'), Sara puts her nutcracker down on the table, inadvertently making a loud clunk noise. Shortly after, Furio repeats the part of Sara's turn (dei gherigli 'of the kernels') immediately preceding the last.

(2) (BiscottiMattina01_2261920)

1 Furio: tipo pesare la farina, 'like weighing the flour'

2 (3.9)/((both continue cracking and shelling walnuts))

3 Sara: eh no prima c'è la sfida

PTC no before $\mathrm{LOC}=$ be.3sG the challenge

'well no first there's the challenge' dei gherigli + di noce, of-the kernels of walnut 'of the kernels of walnut'

+ puts nutcracker down on table with a loud clunk

$6 \quad(0.8)$

7 Furio: dei ghe'RIgli?

of-the kernels

'of the kernels'

$8 \quad(0.5)$

9 Sara: di noce,

'of walnut'

$10 \quad(0.9)$

11 Furio: e che sfida c'è;

and what challenge $\mathrm{LOC}=\mathrm{be} .3 \mathrm{sG}$

'and what challenge is it'

12 (0.3)

13 Sara: eh vedere se ne abbiamo cento grammi o no. PTC see-INF if PTV have-1PL hundred grams or not 'well to see if we have a hundred grams or not' 


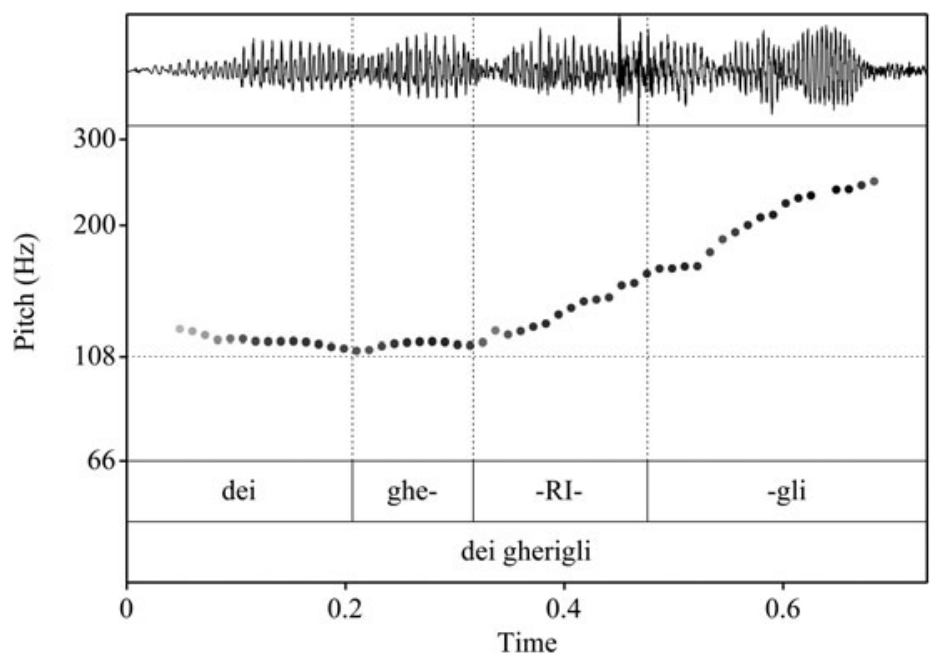

FIGURE 1. Waveform and pitch trace of Furio's repetition (dei gherigli 'of the kernels') in extract (2), line 7, produced with a RISE FROM HIGH contour to seek completion of what Sara has said.

Plausibly as a result of the loud clunk overlapping with the last segment of Sara's turn, Furio repeats part of her talk up to that segment so as to prompt her to complete it, which Sara then does (line 9). Such requests for completion are typically produced with a RISE FROM HIGH contour (Figure 1), which involves a rise on the last stressed syllable followed by a higher terminal rise. ${ }^{3}$ This type of nuclear contour can be transcribed as $\mathrm{L}+\mathrm{H}^{*}{ }_{i} \mathrm{H} \%$ in ToBI notation. The terminal rise ends up high in the speaker's range and the last syllable is often lengthened to realize the final upstep.

Other-repetitions seeking completion, in Italian as in other languages, may involve syntactically incomplete phrases or clauses that offer a grammatical cue to the type of response that is due next (see e.g. Persson, this issue). In other cases like (2), however, the repeated talk is syntactically complete, which broadens the range of repair operations that a speaker could potentially solicit by repeating it, such as clarification of what it means or confirmation that this is indeed what was said. The prosody of the repetition, therefore, is a crucial indicator of its function in these cases.

\section{Seeking confirmation}

When seeking confirmation, a speaker requests that the previous speaker approve or validate a proposition. In the domain of repair, speakers seek confirmation of a candidate hearing or understanding, that is, of a hypothesis as to what has been said or meant (Schegloff et al. 1977; Heritage 1984:319). This can be accomplished 
through a range of practices, some of which involve reformulating or substantially adding to what has been said, which is then presented to the previous speaker for confirmation (or disconfirmation). Here, however, the focus is on seeking confirmation through the resaying of a word, phrase, or clause from the preceding talk with no or little modification.

We already encountered an example of seeking confirmation in (1), where Sofia repeats Ettore's announcement (in sei siamo 'we are six'), which had come in overlap with her own talk (lines 2-3). After Ettore confirms that this is indeed what he said (sì 'yes', line 6), the participants carry on with their work in the kitchen. This shows that confirmation was an adequate and sufficient response to Sofia's repetition.

In (1), the speaker of the original saying produces the confirmation right away. In the next case (3), the confirming response is somewhat delayed, but the repetition speaker's behavior provides evidence for its conditional relevance.

Gloria is in the process of telling Elvira about the upcoming republication of a famous novel series. Soon after launching the news-telling sequence, however, Gloria has stumbled over the word to refer to a book being published again. While searching for the word (lines 1-7), Gloria solicits Elvira's help, which comes in line 12 ('oh a reprint of a book'). As Elvira offers this solution to the word search, Gloria repeats the key term una ristampa 'a reprint' (line 13).

(3) (Fumatrici02_342615)

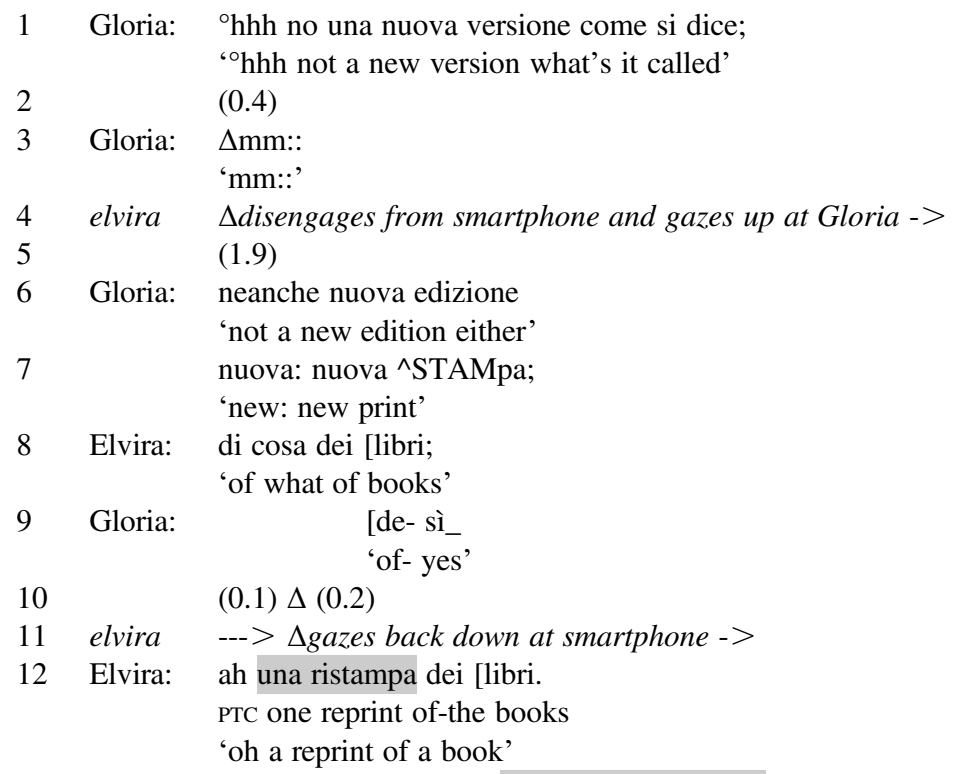

13 Gloria:
$[*$ una ri+^ $\mathrm{STAM}+\mathrm{pa}$ 'a reprint' 
*keeps gazing at Elvira -> + nods +

$$
\begin{aligned}
& \text { (0.9) * } \\
& \text {---->* } \\
& \text { Elvira: } \quad<<\mathrm{p}>\text { s } \Delta \grave{i ̀}_{-}> \\
& \text {'yes' } \\
& \Delta \text { gazes up at Gloria }
\end{aligned}
$$

Gloria: vabè comunque è molto più fedele $\mathrm{a}:: \mathrm{mm}$ 'okay anyway it's much more faithful to:: $\mathrm{mm}$ ' cogli inglesi, 'to the English'

During the word search, Elvira disengages from her smartphone and gazes up at Gloria (line 4). The two maintain mutual gaze until Elvira offers her solution, just before which she gazes back down at her smartphone (line 11). Gloria, however, keeps gazing at Elvira through her repetition of the key term una ristampa 'a reprint' (lines 13-14) and through the silence that follows it (line 16), up until the beginning of Elvira's confirming response (si 'yes'). This shows the speaker's orientation to confirmation as a conditionally relevant response to her repetition before she can resume the news-telling sequence that was suspended by the word search (line 20). ${ }^{4}$

In Trentino Italian, seeking confirmation of a candidate hearing or understanding is typically done with a RISE-FALL contour (Figure 2), which involves a rise on the last stressed syllable followed by a fall, after which, if the utterance continues, the pitch stays low. This type of nuclear contour can be transcribed as $\mathrm{L}+\mathrm{H}^{*} \mathrm{~L} \%$ in ToBI notation. ${ }^{5}$

The association between this RISE-FALL contour and seeking confirmation in Trentino Italian is further supported by the use of the same contour with other practices for seeking confirmation. As mentioned above, confirmation can be sought on candidate understandings which, unlike repetition, involve reformulating or substantially adding to the preceding talk. These 'candidate interpretations' are also typically produced with a RISE-FALL (Rossi 2015:271-73).

As we see in the next section, however, the RISE-FALL contour is also used for actions of displaying surprise. So the recognizability of seeking confirmation must rely on other elements as well. Some of these are prosodic features other than pitch contour which I illustrate in the next section. Here, I want to briefly discuss another element of behavior that seems to be associated with seeking confirmation, namely head gesture. More specifically, requests for confirmation are often accompanied by a single nod of the head, beginning and ending within the repetition turn - as in (3), line 15 . While head nodding has been documented primarily as part of responsive conduct (e.g. Stivers 2008), it has also been observed in initiating actions (e.g. instructions) where it can serve to 'encourage' a preferred 


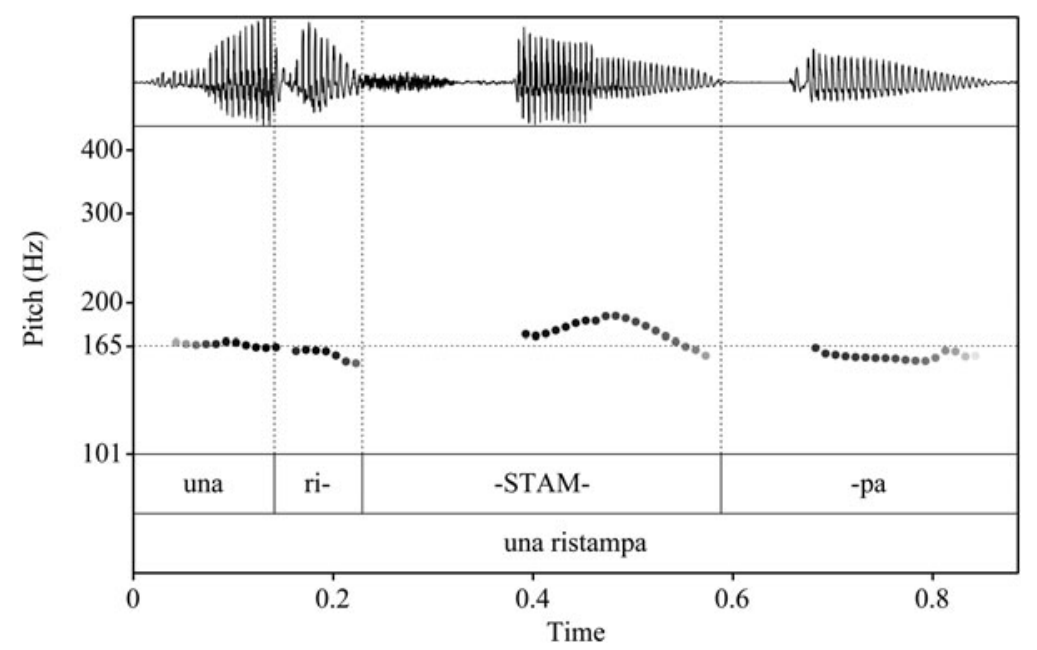

FIGURE 2. Waveform and pitch trace of Gloria's repetition (una ristampa 'a reprint') in extract (3), line 13, produced with a RISE-FALL contour to seek confirmation of what Elvira has said.

response from the recipient (Heath 1992:103-105). This suggests that the head nods that accompany requests for confirmation may be in service of the preference for candidate hearings or understandings to be validated, rather than disconfirmed.

\section{B E Y O N D INIT I A T IN G REPAIR}

In this section, we examine actions that extend beyond initiating repair. This means that the import of the repetition involves more than dealing with a problem of hearing or understanding, often implicating problems of expectation related to a remarkable or inappropriate element of the preceding talk. The relation between initiating repair and actions such as displaying surprise or questioning acceptability has already been extensively discussed in the literature, often with reference to other-repetition (Jefferson 1972; Selting 1996; Schegloff 2007:102-4, 151-55; Svennevig 2008; Benjamin \& Walker 2013; Robinson 2013, among others). Sequences in which a speaker raises a problem of expectation with what has been said share important properties with other-initiated repair, including a halt in progressivity and the concerted effort of participants to address the problem. Crucially, however, the interactional work done in these sequences involves additional dimensions of intersubjectivity beyond mutual understanding, such as the alignment, agreement, or affiliation between participants. Another aspect of the difference with simply initiating repair is that, in actions that go beyond initiating repair, the repetition speaker takes a stance, whether moral or affective, positive or negative, toward what has been said (Wu 2006:78). 
While there is of course a wide range of nuances and colorings that actions in this domain can take, there are also recurrent types that can be identified and contrasted in terms of their social-interactional meaning, consequences, and the alternative kinds of sequential developments they are associated with. As we see below, in this domain, too, prosody plays a central role, along with other elements of behavior.

\section{Questioning acceptability}

Problems of acceptability typically concern the truthfulness, accuracy, or appropriateness of what has been said. While such problems may at times be initially treated as problems of understanding (e.g. Svennevig 2008), speakers have ways of overtly expressing that they are questioning the acceptability of another's talk. In these cases, the action becomes 'negatively valenced' (Schegloff 1997; Wu 2006), conveying that, from the speaker's point of view, the preceding talk is " wrong" and in need of correction' (Benjamin \& Walker 2013:108).

In (4), Clelia and Lisa are resuming a prior topic of conversation, Clelia's fantasy book project, sharing an orientation to the topic as somewhat embarrassing for Clelia yet amusing for both. After they both laugh and giggle at the prospect of talking about it (lines 2-3), Lisa makes an ironic assessment ('what a nice topic', line 5) and Clelia aligns with it with an expression of self-commiseration ('oh my goodness', line 7). A moment later, Lisa adds another assessment, this time about the current state of the book which, she notes, is pieno di spunti, literally 'full of starting points'. ${ }^{6}$ After a notably long silence (line 11), Clelia repeats the term spunti 'starting points'.

(4) (TreCugine_867393)

1 Clelia: ah sì stavi dicendo del mio libro, 'oh yes you were talking about my book'

2 Lisa: a:h $<<:-)>$ sì + heh heh il tuo libro heh heh heh 'o:h yes heh heh your book heh heh heh'

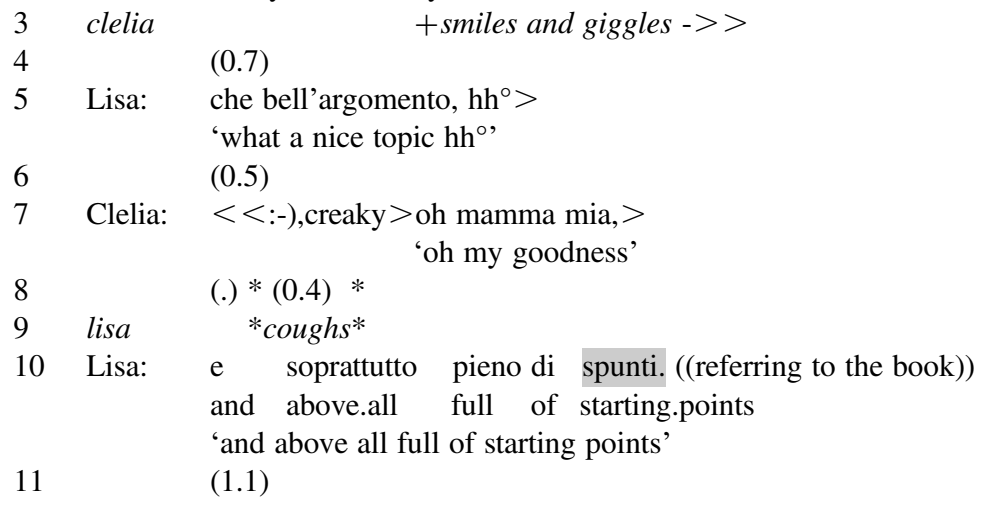


12 Clelia: 'S+PUNti?

'starting points'

15 Lisa: sp + unti_

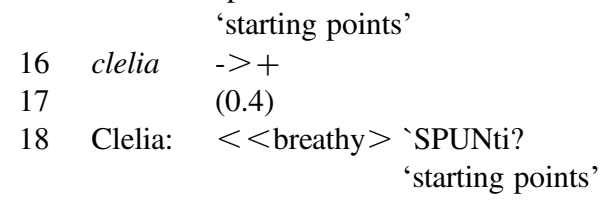

$19 \quad(0.5)$

20 Lisa: $\quad<<$ cresc $>$ ce ne sono tante di cose LOC PTV be.3PL many of things 'there are so many things' to define-INF in-the your book 'to be defined in your book'

24 Clelia: allora di' pieno di cose da definire; then say-IMP.2sG full of things to define-INF "then say "full of things to be defined"

Lisa initially responds by confirming the term she has just used with a selfrepetition (line 15). Clelia then redoes her other-repetition with breathy voice, almost chuckling, indicating that confirmation is not the response she is after (line 18). At this point, Lisa gives a different response ('there are so many things to be defined in your book', lines 20-21), explaining what she meant and justifying her earlier assessment. Her defensive stance here is further signaled by a rapid change in the volume of her talk which becomes noticeably louder (crescendo).

What Clelia does next (lines 22-24) reveals the compound nature of the problem

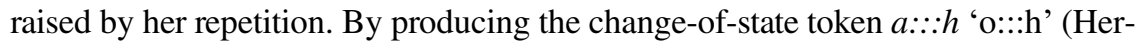
itage 1984), she indicates the resolution of a trouble in understanding; at the same time, by suggesting an alternative expression that, in her view, Lisa ought to have used ("then say "full of things to be defined"), Clelia makes explicit her orientation to Lisa's initial expression as inappropriate.

In sum, the development of the interaction demonstrates that the repetition here is designed to raise a problem that extends beyond understanding and involves the acceptability of what has been said.

Consider another case (5), taken from the same interaction as (2). As Sara and Furio continue their work of cracking and shelling walnuts, Sara begins to talk about her plans for the afternoon, when she is expected back home to take part in another food preparing activity with her family. When the extract begins, Sara 
attempts to recruit Furio's help for this later activity ('would you like to help us', line 1), to which he initially responds to with a dead-pan refusal ('well: (0.5) I'd rather not', lines 4-6). After Sara gives him an ironic 'thanks' (line 8), Furio expands the sequence with an account, which he formulates tentatively ('I believe', line 9) and vaguely ('I have stuff to do this afternoon', line 10). Sara then repeats the central part of the account ('you have stuff to do').

(5) (BiscottiMattina01_1249880)

1 Sara: vuo- vuoi aiutarci

'wou- would you like to help us'

2 che ne abbiamo tipo $<<$ laughing $>$ cento da fare, $>$ 'since we have like a hundred to do'

$3 \quad(0.7)$

4 Furio: ma:

PTC

'well:'

$5 \quad(0.5)$

6 Furio: $\uparrow$ anche no, also no

'I'd rather not'

$7 \quad(0.4)$

8 Sara: $\quad<<$ :-), breathy $>$ grazie_ $>$ 'thanks'

9 Furio: no non è quello è che $<<\operatorname{dim}>$ mi sa che no not be.3sg that be.3sg COMP 1sG.DAT feel-3sg COMP 'no it's not that - it's that I believe'

10 ho da fare questo pomeriggio. $>$ have-1SG to do-INF this afternoon 'I have stuff to do this afternoon'

11 Sara: hai da 'FAre, have-2SG to do-INF 'you have stuff to do'

$12 \quad(1.1)$

13 Sara: cos'hai da fare.

what $=$ have-2sG to do-INF

'what do you have to do'

14 Furio: $<<$ creaky $>$ non mi ricordo qualcosa. $>$ not RFL remember-1SG something 'I don't remember - something'

$15 \quad(0.9)$

16 Sara: ((snorts))

17 in realtà è una scusa $<<\operatorname{dim}>$ per non venire_ $>$ in reality be.3sg one excuse for not come-INF 'it's actually an excuse not to come' 


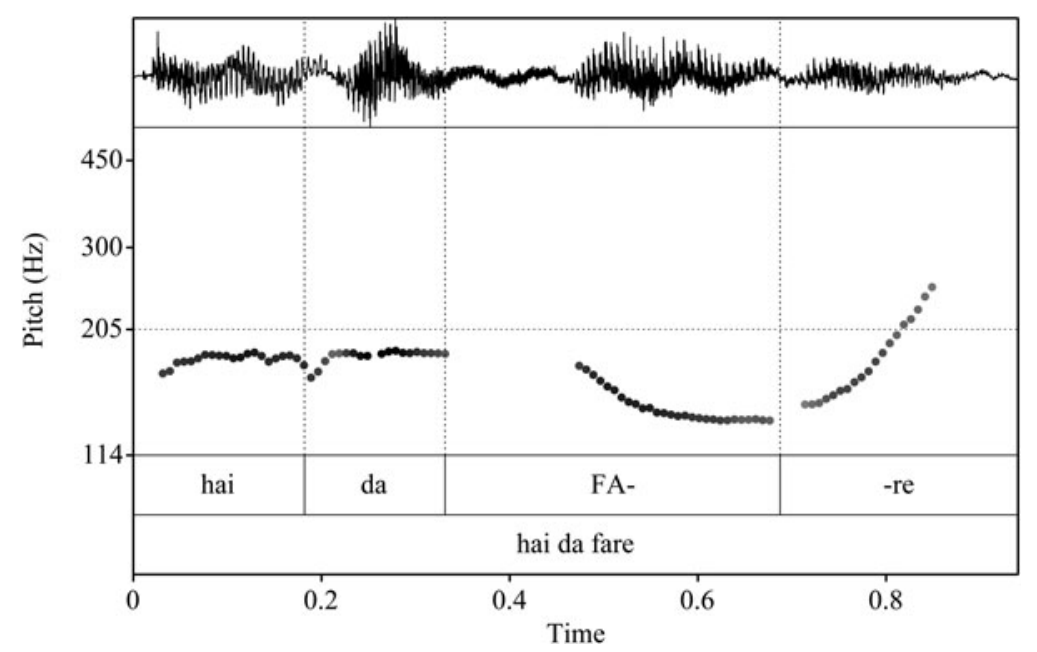

FIGURE 3. Waveform and pitch trace of Sara's repetition (hai da fare 'you have stuff to do') in extract (5), line 11, produced with a RISE FROM LOw contour to question the acceptability of what Furio has said.

The issue of truthfulness and appropriateness of Furio's account, already foreshadowed in its flimsy formulation, becomes apparent in the development of the sequence following Sara's questioning repetition. After a notably long silence (line 12), Sara follows up on the repetition by probing into Furio's claim ('what do you have to do'). At this point, he reveals his tongue-in-cheek bluff ('I don't remember - something', line 14); Sara smiles, snorts, and calls out the bluff ('it's actually an excuse not to come', line 17).

The pitch contour used by repetition speakers in (4) and (5) is a RISE FROM LOW, which involves falling or low pitch on the last stressed syllable followed by a terminal rise. This type of nuclear contour can be transcribed as $\mathrm{H}+\mathrm{L}^{*} \mathrm{LH} \%$ in ToBI notation. ${ }^{7}$ The use of this contour often goes together with low register, illustrated in Figure 3, where the whole pitch configuration begins and remains below the middle of the speaker's range until the final rise.

The actions of questioning acceptability in (4) and (5) can be further characterized in light of the repetition speaker's stepwise approach to dealing with the problem of acceptability, which involves creating opportunities for the previous speaker to justify, modify, or back down from what they have said (see also Rossi 2015:275-77). In both (4) and (5), this begins with the speaker leaving a silence after the repetition. Then, in (4), after receiving an inadequate response, the speaker redoes the repetition; in (5), the speaker asks a follow-up question and, after receiving an equivocal answer, leaves another silence. More generally, speakers of RISE FROM LOW repetitions only gradually proceed to correct, reject, or disaffiliate with what has been said. Even in the face of resistance, the repetition 
speaker leaves space for the previous speaker to revise the problematic expression or action before openly challenging it. As Persson (this issue) argues, this is grounds to define the action accomplished by such repetitions as a prechallenge to what has been said, which echoes earlier analyses of other-initiated repair practices as a vehicle for 'pre-' or 'incipient' disagreement or disaffiliation (Jefferson 1972:310-12; Schegloff 2007:102-4, 151-55, and references therein).

An analysis of RISE FROM LOW repetitions as prechallenges is reinforced by contrast with another set of questioning repetitions that exhibit a different pattern. Here, the way in which the sequence unfolds shows a distinct orientation by the repetition speaker: rather than leaving space for the previous speaker to revise the problematic talk, the speaker designs the repetition and her subsequent actions so as to express disagreement or disaffiliation directly. In other words, what the speaker does in these cases is better described as an outright challenge. As we see below, this distinct way of questioning the acceptability of what has been said is reflected in the speaker's use of another pitch contour.

In (6), Ada has been seeking her sister Cinzia's backing on a proposal concerning an apartment they own together. The proposal is to make a complaint to the current tenant for mishandling. Cinzia's response to the proposal is shown in lines $1-3$, where she resists the proposal by saying that she 'doesn't see the argument', meaning that she does not see a sufficient basis for making the complaint. As Cinzia continues her response with further material (line 3), Ada cuts in with a questioning repetition.

(6) (NataleCucina02_2252546)

\begin{tabular}{|c|c|c|c|}
\hline 1 & Cinzia: & $\begin{array}{llll}\text { n- io } & \text { s- s- s- } & \text { sono } & \text { sincera. }{ }^{\circ} \mathrm{h} \\
\text { n- } 1 \text { sG.NOM } & \text { s- s- s- } & \text { be. } 1 \mathrm{sg} & \text { sincere } \\
\text { 'n- I a- a- a- I'll be } & \end{array}$ & \\
\hline 2 & & $\begin{array}{l}\text { non vedo } \mathrm{mm} \text { : la: }<<\text { all }>\text { l'argomentazione; } \\
\text { not see-1sG } \mathrm{mm} \text { the the }=\text { argument } \\
\text { 'I don't see } \mathrm{mm} \text { : the: the argument' }\end{array}$ & \\
\hline 3 & & $\begin{array}{l}\text { tra l'altro }>\text { sem en deficit ancora noi } \\
\text { among the }=\text { rest be.1PL in deficit still } 1 \text { PL.NOM } \\
\text { 'besides we're still in deficit because }{ }^{\circ} \mathrm{h} \text { ' }\end{array}$ & $\begin{array}{l}\text { per }+ \text { ch*é_}^{\circ}{ }^{\circ} \mathrm{h} \\
\text { because }\end{array}$ \\
\hline 4 & $a d a$ & & $\begin{array}{l}+ \text { furrows } \\
\text { eyebrows }->\end{array}$ \\
\hline & & & $\begin{array}{l}\text { *leans } \\
\text { forward -> }\end{array}$ \\
\hline 6 & Ada: & $\begin{array}{l}\uparrow \uparrow \text { non } \quad \text { vedi } \quad \text { l'argome }] \mathrm{n}+\mathrm{ta}{ }^{\wedge} \mathrm{ZIOn}\left[\mathrm{e},{ }^{\circ} \mathrm{h}\right]= \\
\text { not see-2sG the = argument } \\
\text { 'you don't see the argument' }\end{array}$ & \\
\hline & Cinzia: & $\begin{array}{l}\text { [ non riusci- } \\
\text { not manage- } \\
\text { '(we) can't manag- }\end{array}$ & \\
\hline
\end{tabular}




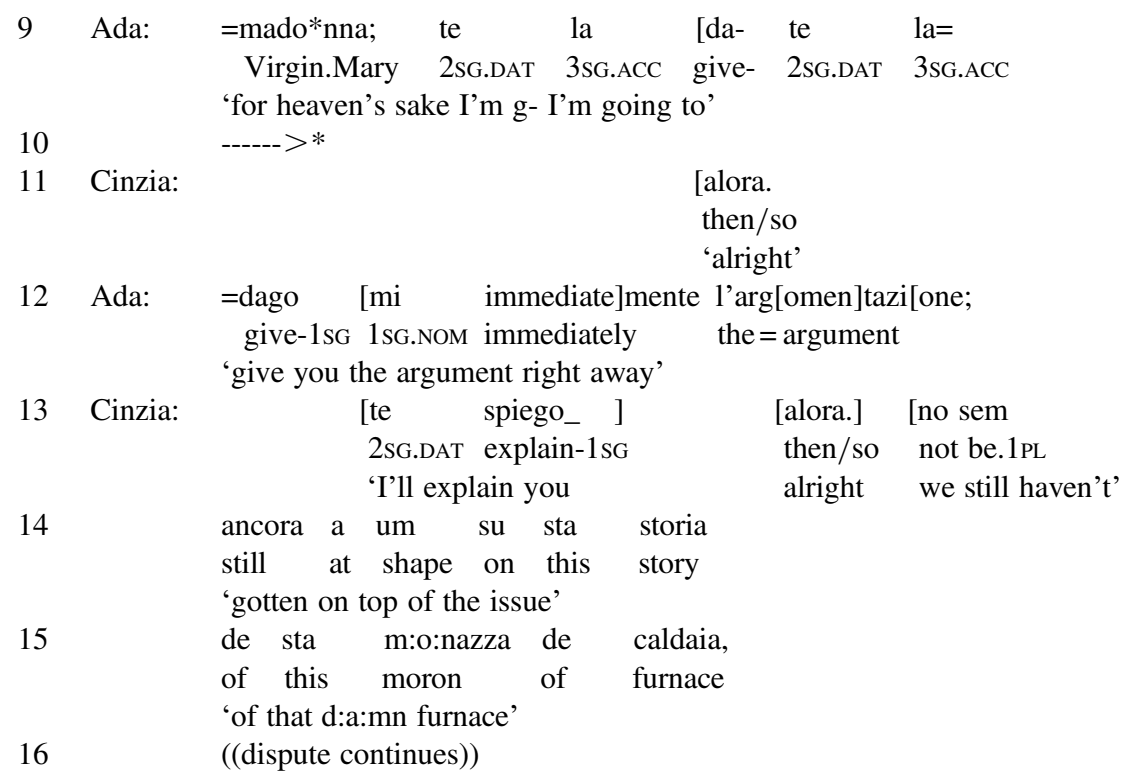

By repeating the key component of Cinzia's preceding talk ('you don't see the argument'), Ada questions the acceptability of her view and the stance that she is taking against Ada's proposal. In response, Cinzia first confirms that this is indeed her position ('no', line 8) and shortly after begins to defend it (lines 11,13-15). Before she gets to this, however, Ada has already moved forward with expressing overt disagreement and disaffiliation with her, first with an exclamation of stupefaction and mild indignation (madonna, roughly 'for heaven's sake'), and then with a counter to Cinzia's skepticism ('I'm going to give you the argument right away'). Note that this part of Ada's talk is latched onto her repetition turn (lines 6, 9, 12).

Consider another example (7), involving Sofia and Ettore, from (1) above. Before the extract begins, the couple has started disputing over what they should do with an old bottle of liquid soap that is sitting in their bathroom, which Ettore wants to keep using and Sofia wants to throw away instead. The bottle is nearly empty and the remaining soap at the bottom has partly solidified into pieces. When the extract begins, Sofia is claiming that, in an effort to recover the remaining soap, Ettore has added water to the bottle to try to 'melt' the pieces, unsuccessfully. In response, Ettore questions Sofia's claim by repeating the pronoun $t u$ 'you' with a deictic shift to io 'me'.

(7) (BrentoPrep_2323675)

1 Sofia: son dei pezzi di sapone intero be.3sG some pieces of soap whole 'they are whole pieces of soap' 


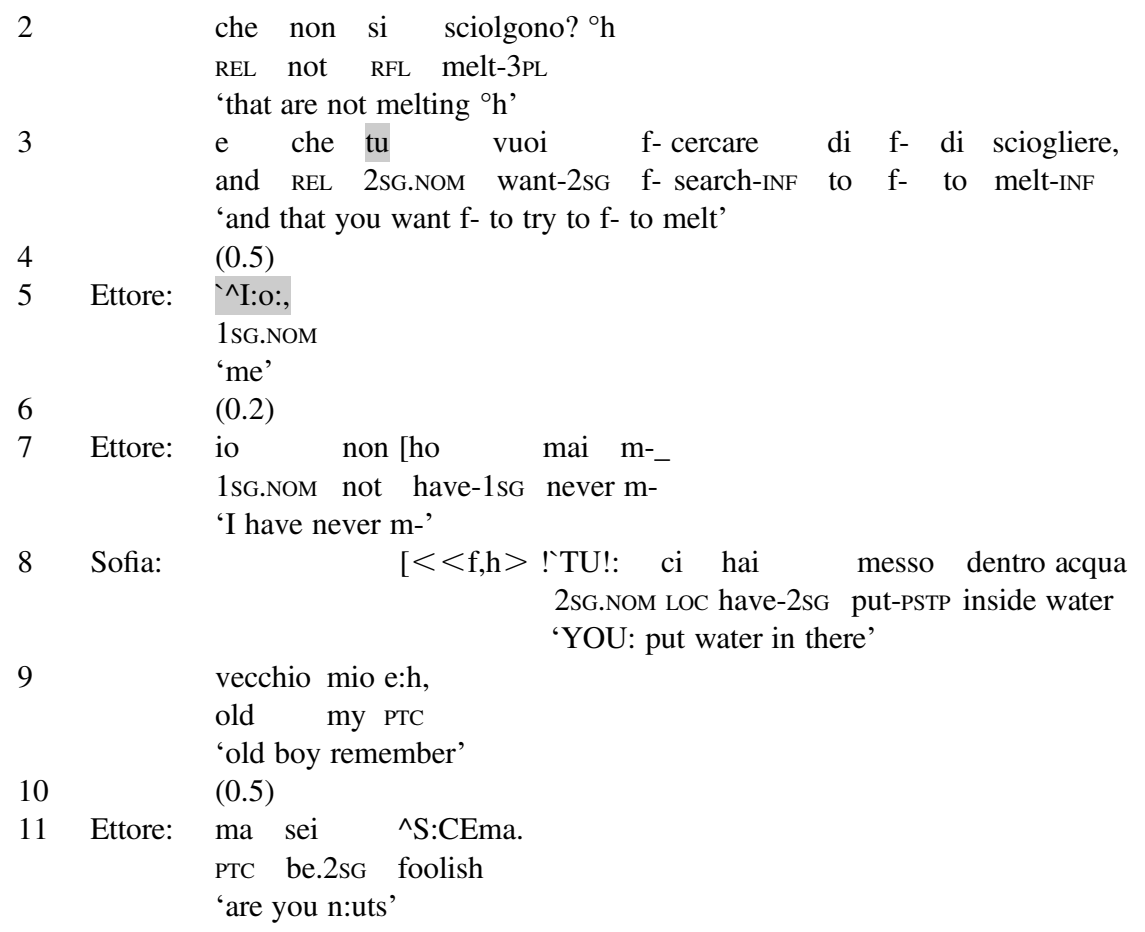

Sofia responds to Ettore's questioning repetition by emphatically confirming and strengthening her claim (lines 8-9). Before she begins responding, however, Ettore has already proceeded to express overt disagreement ('I have never $\mathrm{m}^{-}$', line 7). Though this follow-up turn is cut off as Sofia comes in with her loud and highpitched response, Ettore then upgrades his challenge with an even stronger expression of disaffiliation ('are you n:uts', line 11).

In sum, unlike in (4) and (5), in (6) and (7) the repetition speaker does not create an opportunity for the previous speaker to modify or backtrack on what they have said. Although the repetition still formally allows the previous speaker to respond with confirmation, justification, or the like, the development of the sequence leaves no space for participants to reconcile their positions before disagreement and disaffiliation are made overt. The action launched by the questioning repetition therefore does not adumbrate but rather delivers a challenge outright.

This distinct way of questioning acceptability is typically designed with a SCOOPED RISE-FALL-RISE contour (Figure 4), which begins with a late rise on the last stressed syllable, followed by a fall, and then by a terminal rise. The low target preceding the rise on the stressed syllable is often realized as a falling movement. This type of nuclear contour can be transcribed as $\mathrm{L}^{*}+\mathrm{H} \mathrm{LH} \%$ in ToBI notation. 


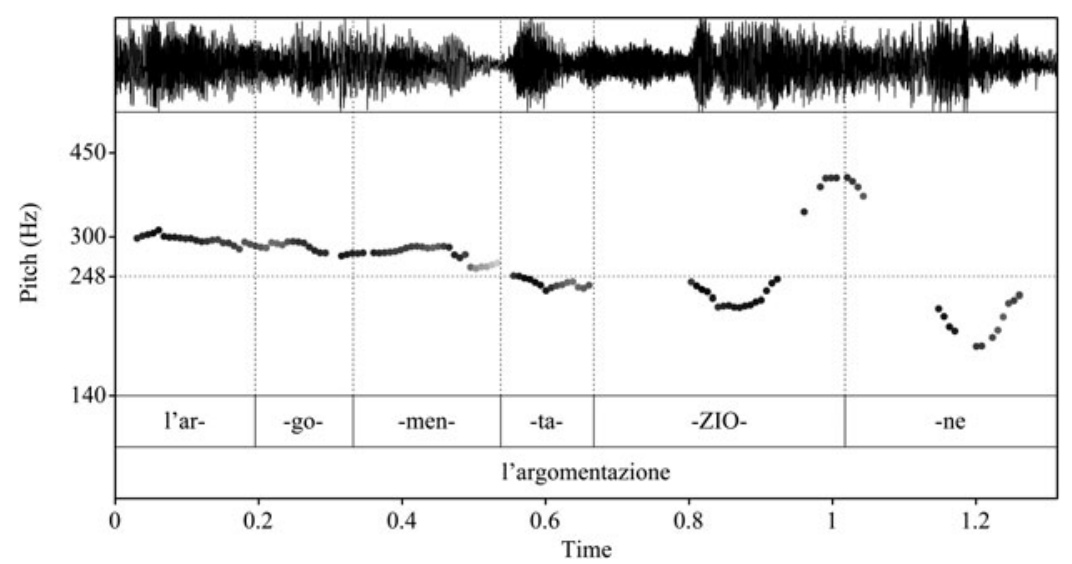

FIGURE 4. Waveform and pitch trace of the latter part of Ada's repetition (l'argomentazione 'the argument') in extract (6), line 6, produced with a SCOOPED RISE-FALL-RISE contour to question the acceptability of what Cinzia has said.

Having drawn a distinction between prechallenges and challenges, it is also important to recognize their similarity as actions of questioning acceptability. In both cases, what the speaker does is negatively valenced, adumbrating or exposing disagreement and disaffiliation between participants. This import is in contrast both with actions of simply initiating repair and other actions that extend beyond initiating repair without questioning the acceptability of what has been said.

Before we turn to the analysis of these other actions, I want to discuss an element of visible behavior that is recurrently found in questioning repetitions. In this case, it is an element of the speaker's facial expression, and specifically the movement or configuration of the eyebrows. Figure 5 shows stills of the speaker's face in extract (4) during the original turn (left) and during the repetition turn (right).

During the repetition turn, the speaker's eyebrows are furrowed, that is, lowered and drawn together, which often produces vertical wrinkles above the nose. This facial expression is also referred to as a 'frown' (Darwin 1872:222). In the system developed by Paul Ekman and his colleagues to code facial action (Ekman, Friesen, \& Hager 2002), the eyebrow furrow is identified as AU (Action Unit) 4. In extracts (4) and (6), the speaker's eyebrows begin to furrow near the onset of the repetition turn and are maintained in this position through at least half of the turn.

Studies of facial expression and its relation to emotions have shown that eyebrow furrows or frowns are linked to feelings of displeasure and difficulty, as well as to more specific negative emotions such as anger, sadness, and disgust (Russell 1997; Smith \& Scott 1997). More recently, conversational studies have observed that eyebrow furrows can occur as speakers begin to produce negative assessments and other disaffiliative actions that are at odds with a preceding action or stance 


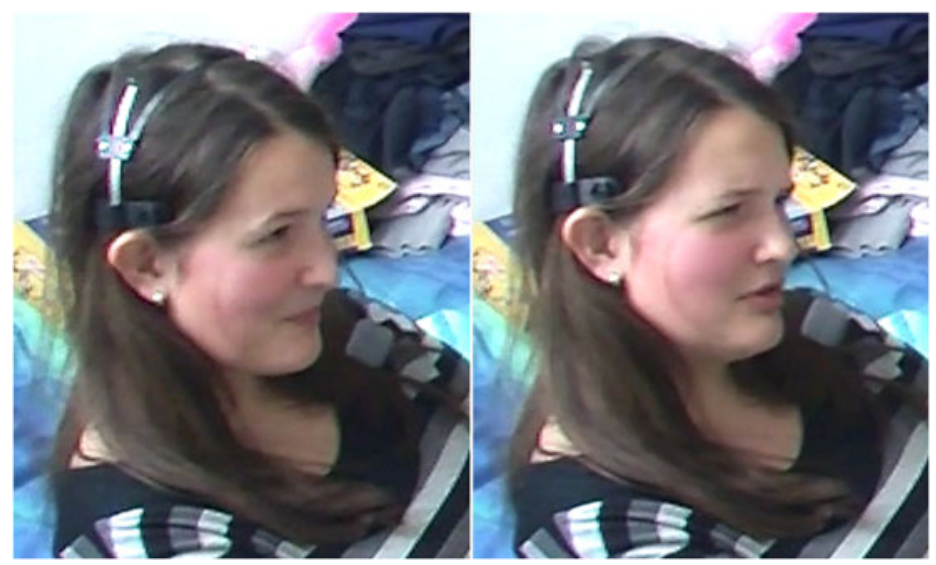

FIGURE 5. Frames from extract (4): on the left, Clelia's facial expression during the original turn (line 10); on the right, Clelia's facial expression during the repetition turn (line 12). The eyebrows are furrowed as she questions the acceptability of what Lisa has said.

expressed by another participant (Kaukomaa, Peräkylä, \& Ruusuvuori 2014). This is consistent with the occurrence of eyebrow furrows in other-repetition sequences, where they accompany negatively valenced actions of questioning the acceptability of what another has just said.

\section{Displaying surprise}

Displaying surprise is another type of action that extends beyond initiating repair (e.g. Selting 1996). When displaying surprise, a repetition speaker conveys a stance toward an unexpected, remarkable element of what has been said, often implicating affective involvement. While the unexpected element may be good or bad, pleasing or disappointing, an action of displaying surprise is oriented to building a shared stance between participants (Wilkinson \& Kitzinger 2006). In this sense, the action is positively valenced, aimed at alignment and affiliation, in contrast with the negative valence of questioning acceptability, which instead leads to disalignment and disaffiliation.

In (8), Anna is telling Diego about her recent catch-up with a mutual friend who had been out of circulation. After commenting on the friend's profile photo on a messaging application, Anna offers the news that the friend and his girlfriend broke up. As she completes the turn, Diego thrusts his head forward and repeats the clause 'they broke up'.

(8) (Diego\&Anna_3112481)

1 Anna: no in realtà c'ha la fotina piccola in Messenger_ 'well actually he has a small photo on Messenger' 


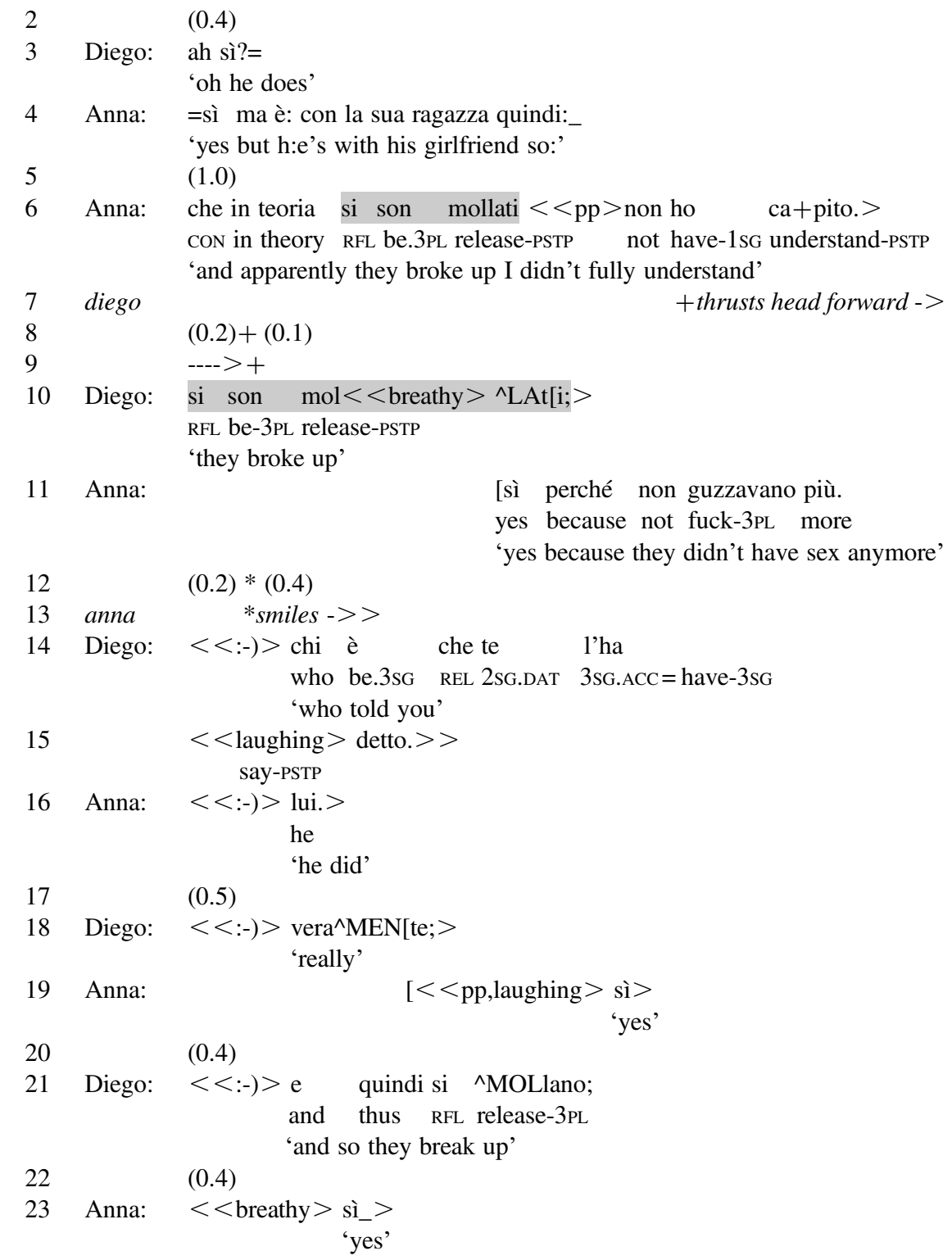

There are several aspects of this sequence that distinguish it from both initiating repair and questioning acceptability. Starting in overlap with the last bit of Diego's repetition, Anna produces a composite response that includes both confirmation ('yes') and elaboration of the news ('because they didn't have sex anymore'). 
A moment later, she begins to smile (line 13), coloring her telling with amusement. Diego joins in the amusement by smiling back as he asks Anna who told her about the intimate detail of the story (lines 14-15), with the last bit of his turn infused with laughter. The shared smiling and laughing continues in the following lines, reinforcing the affiliation between the participants.

After displaying surprise, speakers typically follow up by soliciting further details of a story and by amplifying or otherwise pursuing their stance with additional expressions of surprise (Selting 1996; Wilkinson \& Kitzinger 2006). In this sequence, we can note Diego's expression of 'ritualized disbelief' (Heritage 1984:339) at the reason for the breakup ('really', line 18) followed by more astonishment at the news ('and so they break up', line 21).

Consider another case (9). Four friends have just finished a card game and are now calculating each player's score, with Alfio acting as the score keeper. The goal in this game is to earn the lowest number of points possible. Alfio and Seba have emerged as the clear winners in the just-completed round, both managing to earn zero points (lines 1-3), while Marco and Vanda have instead emerged as the losers. As the participants turn to assessing how badly Marco and Vanda have lost, Marco announces that he got three points (lines 5, 8), which is in fact not a bad score at all. A moment later, Seba repeats the score to display his surprise (line 11).

(9) (Hearts01_1053471)

1 Alfio: ze:ro? ((writes down score)) 'zero'

$2 \quad(0.5)$

3 Alfio: zero? ((writes down score)) 'zero'

$4 \quad(0.5)$

5 Marco: io ne ho f[atti_ ((flips through cards))

1SG.NOM PTV have-1sG make-PSTP 'I got'

6 Alfio:

[quant'ala fahow. much $=$ have -3 sG $=$ sCL make'how many did she g-'

$\begin{array}{lll}7 & & (.) \\ 8 & \text { Marco: } & \begin{array}{l}\text { tre. } \\ \text { 'three' }\end{array} \\ 9 & & (0.1)+(0.2) \\ 10 & \text { seba } & \quad \text { +raises eyebrows }-> \\ 11 & \text { Seba: } & \text { ^TRE; } \\ & & \text { 'three' } \\ 12 & & ------> \\ 13 & & (0.2)\end{array}$




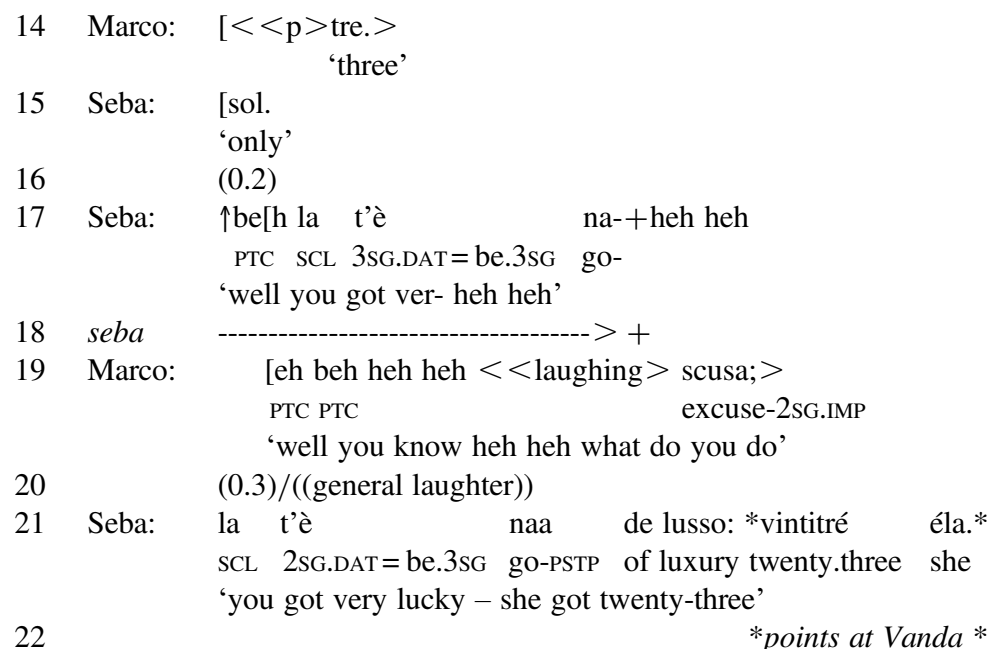

Similarly to (8), the import of the repetition as a display of surprise is evidenced in the way the speaker follows up on it. In overlap with Marco's confirming response ('three'), Seba reveals the clash of expectations motivating his surprise ('only', line 15), conveying that he had anticipated Marco to get a higher score - therefore a worse outcome - out of the game. Seba then begins to say 'well you got ver-' (line 17), plausibly going for 'you got very lucky', and completes the turn a moment later (line 21), after Marco jovially pushes back against Seba's surprise sparking general laughter.

In Trentino Italian, displays of surprise such as those in (8) and (9) are designed with the same RISE-FALL contour found in other-repetitions seeking confirmation. Their sound pattern, however, differs from that of requests for confirmation on another dimension: by including features of 'large' (Pillet-Shore 2012) or 'upgraded' prosody (Curl 2005; Ogden 2006). The most recurrent of these is wide pitch span, with the peak of the RISE-FALL contour going up high in the speaker's range. Figure 6 illustrates this for Diego's repetition in (8).

The contour is only partially traced as the latter part of the utterance is very breathy, but we can clearly see the pitch spanning from around mid to high up in Diego's range, with the peak of the rise reaching a maximum of $303 \mathrm{~Hz}$ and the terminal fall going back down to $122 \mathrm{~Hz}$, for a total of 15.7 semitones (ST). Diego uses the same RISE-FALL contour with a similarly wide span on two other occasions in the extract, as he produces further expressions of surprise: vera^ ${ }^{\wedge} E N t e$ 'really' (line 18) and e quindi si ^MOLlano; 'and so they break up' (line 21). Though somewhat narrower than that of the repetition, the pitch span of these turns covers about an octave-11.9 ST $(238-120 \mathrm{~Hz})$ and 12.1 ST $(229-114 \mathrm{~Hz})$ respectively. This pattern lends further support to the association between a RISE-FALL contour with 


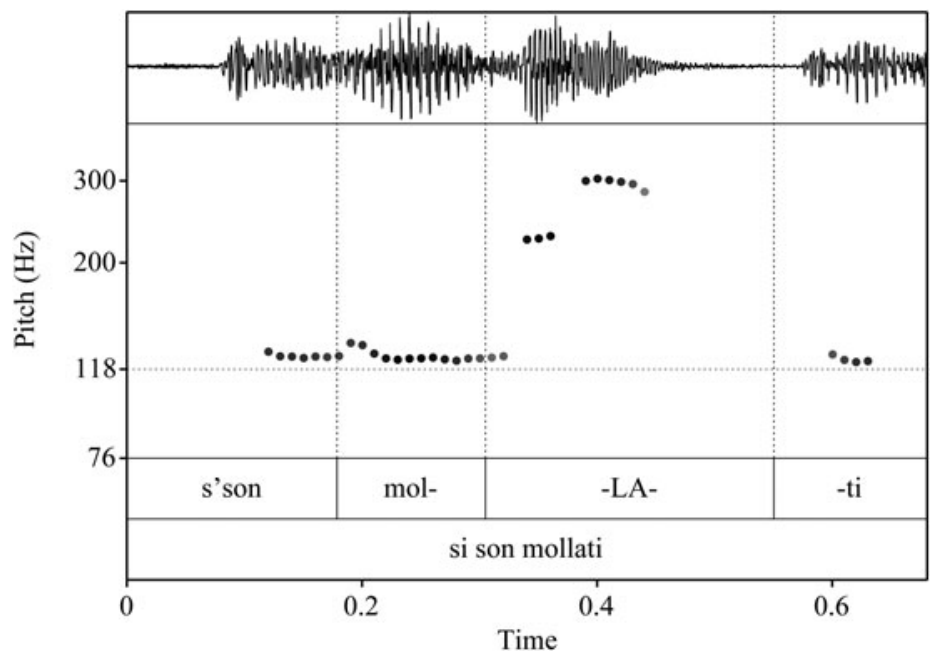

FIGURE 6. Waveform and pitch trace of Diego's repetition (si son mollati 'they broke up') in extract (8), line 10, produced with a RISE-FALL contour and a wide span to display surprise at what Anna has said.

wide span and displaying surprise. In (9), the pitch span of Seba's repetition is even wider, with an exceptional excursion of 19.7 semitones $(338-108 \mathrm{~Hz})$. These values contrast with those of the narrower pitch spans found in the repetitions seeking confirmation in (1) and (3)-7.5 ST $(228-148 \mathrm{~Hz})$ and 4.3 ST (190-148 Hz) respectively. ${ }^{8}$

Alongside prosody, visible behavior contributes to marking this type of action from others, creating a particularly meaningful contrast with the facial expression found in questioning repetitions. Instead of eyebrow furrows, displays of surprise are typically accompanied by eyebrow raises (see Figure 7). In this movement, identified as AU 1+2 in Ekman and colleagues' coding system (2002), the eyebrows are lifted up at both ends and, as a result, the skin on the forehead is bunched up, forming horizontal wrinkles in some people.

Eyebrow raising has been linked to the expression of surprise since Darwin (1872:278), but it has also been shown to have a broad range of functions and meanings in communication (e.g. Chovil 1991). What is important here is how eyebrow raises contrast with furrows in the context of an other-repetition sequence, strengthening the distinction between negatively and positively valenced actions that extend beyond initiating repair.

\section{O THER THA N I I T I A T N G R E P A R}

In this section, we leave the domain of actions that involve initiating repair to examine actions that are alternative to it. Other-repetition can accomplish a range 


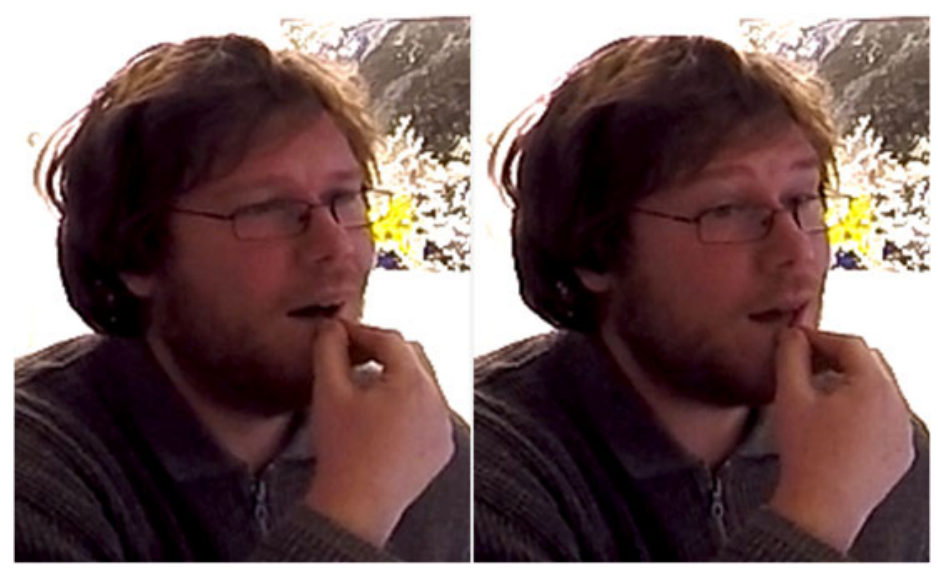

FIGURE 7. Frames from extract (9): on the left, Seba's facial expression during the original turn (line 8); on the right, Seba's facial expression during the repetition turn (line 11). The eyebrows are raised as he displays surprise at what Marco has said.

of actions other than initiating repair, as documented both in prior literature and in other contributions to this special issue (see e.g. Stevanovic, Hakulinen, \& Vatanen, this issue; Persson, this issue). In what follows, I focus particularly on two types of action that stand out in my data.

\section{Seeking confirmation prospectively}

As we have seen, confirmation is a common type of response that can be relevantly produced next to most types of action surveyed so far, except requests for completion. The sequential and preference status of confirmation, however, is not the same across actions. For instance, while confirmation is a conditionally relevant response to a hearing or understanding check, it is insufficient in and of itself after a display of surprise, and it is dispreferred to a questioning repetition. These differences are reflected in the use of alternative confirmation tokens and in other aspects of their design that shed light on the nature of the action they are responding to (see Sorjonen 1996; Persson 2015, this issue, among others).

In (10), participants are playing a board game that involves trading resources such as grain, brick, ore, and wool. We join the game during Vanda's turn, as she asks whether anyone has grain to trade (line 1). After receiving a negative response (lines 3-4), Vanda begins to ask a similar question about brick ('does anyone', line 5). This second question, however, morphs into an assessment that, as far as she can tell, nobody has brick ('well brick nobody has it'). In line with this, Vanda prepares to hand over the dice (lines 6,10) and moves to end her turn at the game by saying ciao 'bye' (line 9). While this happens, however, Franco responds that he does have brick to trade (l'argilla ce l'ho io 'brick I 
have it', line 8). Vanda then retracts the hand holding out the dice (line 10) and repeats part of what Franco has said (ce l'hai 'you have it').

(10) (Rigoni02_214206)

1 Vanda: qualcuno ha un ${ }^{\wedge}$ GRAno? 'does anyone have grain'

$2 \quad(0.3)$

3 Franco: $<<1>$ magari, $>$ (.) [io non ne ho proprio grani_

4 Serena: $\quad \begin{array}{ll}\text { I have no grain } \\ {[<<\mathrm{pp}>\text { no:, }>}\end{array}$ 'no'

5 Vanda: qualcuno $\downarrow$ beh l'argilla + non ce l'ha nessuno? someone PTC the $=$ ore not LOC 3 SG. $A C C=$ have-3sG nobody 'does anyone - well brick nobody has it'

6 7

8 Franco: $\uparrow l$ 'a[r+gill]a ce l'ho +io. the = clay $\quad$ LOC $3 \mathrm{SG} . \mathrm{ACC}=$ have-1SG 1 SG.NOM 'brick I have it'

9 Vanda: $[\mathrm{c}+$ iao $]$ hi/bye 'bye' $---->+$ holds out dice ----------------> + retracts hand -> ce $\wedge$ 'HAi+? LOC 3sG.ACC $=$ have-2sG 'you have it'

12 -----------> + picks cards back up ->>

13 Franco: $\mathrm{mm} \mathrm{hm}$ ?,

$14 \quad(0.2)$

15 Vanda: ti do un minerale Franco, 'I'll give you ore Franco'

Vanda's repetition does not deal with a problem of hearing or understanding. Her hand retraction (line 10) and picking the cards back up (line 12) demonstrate that she has sufficiently understood the import of Franco's preceding talk as opening up the opportunity to trade resources. Put another way, there is no 'barrier' here that needs to be removed in order for intersubjectivity to be maintained and for progress to resume (Hayashi, Raymond, \& Sidnell 2013:13). Instead, Vanda's repetition is sensitive to the sequentially pivotal position in which she finds herself in, at a point where a course of action that was on its way to be concluded is being reopened.

It has long been noted that practices for other-initiation of repair can be used to deal with 'sequential trouble' such as an abrupt shift in topic, or an inapposite and 
possibly disaffiliative action (Drew 1997). Here, however, Franco's action is both affiliative and aligning with the question that Vanda had begun to ask ('does anyone', line 5). Vanda produces the repetition as she restructures her own actions in light of the complex development of the sequence.

Seeking confirmation of a candidate hearing or understanding is a 'backward-looking' action (Schegloff 2007:106) that halts the progress of conversation to solve a problem with the previous talk. In (10), Vanda's request for confirmation has instead a 'forward-looking' or prospective orientation to what is coming next. The co-occurring retraction of her hand and picking up of the cards prepare the ground for her subsequent action of trading ('I'll give you ore Franco', line 15). In this environment, the work accomplished by the repetition can be characterized as seeking confirmation of the conditions for a subsequent action, ratifying a shift in trajectory, and projecting continuation of the sequence.

Similar actions of seeking confirmation with a prospective orientation are found in cases where the repetition speaker is involved in multiple concurrent tasks. ${ }^{9}$ Here, too, the repetition serves the management of overlapping trajectories of action. This kind of sequential work seems to distinguish this usage of repetition from related ones such as 'mulling over' a question (Kelly \& Local 1989:272ff) or 'temporizing' before giving an answer (Bolden 2009:136-38) which are instead accomplished within the same trajectory or sequence of action. Also, in these previously described usages, repetitions are NOT designed to elicit a response. The type of action exemplified in (10), by contrast, is an action of seeking confirmation, and normally receives it.

Coming now to how confirmation reflects the action it responds to, we can note that in (10) the previous speaker confirms what he has said with $\mathrm{mm} \mathrm{hm}$. As an acknowledgement token, $\mathrm{mm} \mathrm{hm}$ has been characterized as weaker, or less strong, than a polar interjection ('yes') (e.g. Gerhardt \& Beyerle 1997). Also, $\mathrm{mm} \mathrm{hm}$ is an 'archetypical continuer' (Gardner 2001:116) that projects more to come from the other speaker, a function that is reinforced by final rising pitch. The use of $\mathrm{mm} \mathrm{hm}$ and other similar response tokens thus provides further evidence for the prospective character of requests for confirmation like the one in (10).

In Trentino Italian, seeking confirmation prospectively is produced with a RISE-FALL-RISE contour (Figure 8), which involves a rise on the last stressed syllable, followed by a fall, and by a terminal rise. This type of nuclear contour can be transcribed as $\mathrm{L}+\mathrm{H}^{*} \mathrm{LH} \%$ in ToBI notation.

To complete our survey, I present a case of registering what another has said, a type of action that has been already documented in the literature (e.g. Sorjonen 1996; Schegloff 1997; Persson 2015). Registering is alternative to initiating repair in that, instead of signaling a problem of hearing or understanding, the speaker acknowledges receipt of the preceding talk, which is 'taken in' rather than problematized.

In (11), Sofia and Ettore are talking about their vacation plans. Before the extract begins, Sofia has announced that she has reflected on their options and that she 


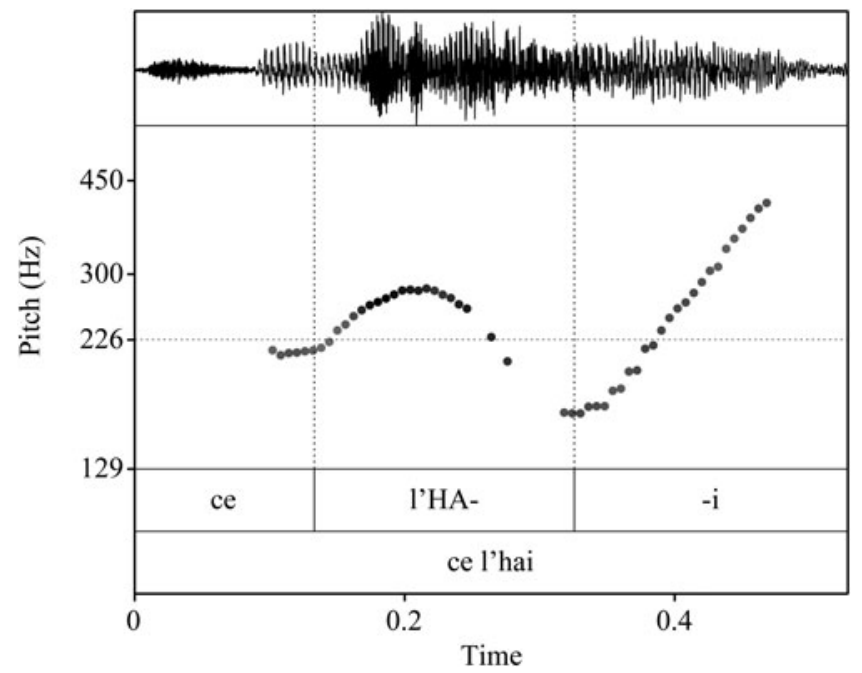

FIGURE 8. Waveform and pitch trace of Vanda's repetition (ce l'hai 'you have it') in extract (10), line 11 , produced with a RISE-FALL-RISE contour to seek confirmation prospectively.

wants to present her destination preferences to Ettore. We join the interaction as Ettore gives her the go-ahead (line 1). Sofia then starts off by announcing that she is ruling out northern Europe (l'Europa del nord no 'northern Europe no', line 6). ${ }^{10}$ In response, Ettore repeats the last word of Sofia's turn.

(11) (BrentoPrep_1452708)

1 Ettore: eh dimmi:[:

2 Sofia: [eh.

'alright tell me::'

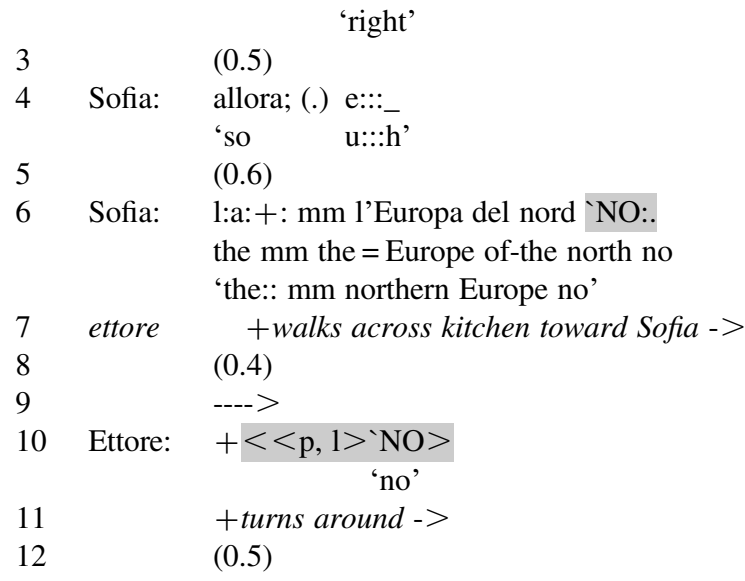




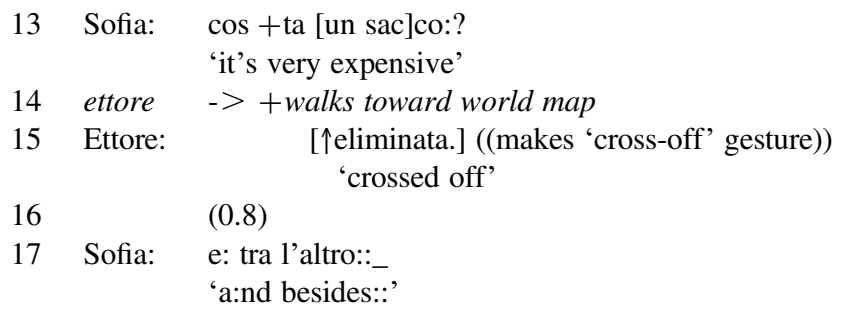

Ettore's conduct around the repetition illuminates the action he is performing by it. Before Sofia utters the word 'no' at the end of her turn, which specifies what her preference about northern Europe is, Ettore can be seen walking across the kitchen toward Sofia. During the short silence that follows the announcement (line 8), he slows down, and then swiftly turns around as he produces the repetition (line 11), heading back in the opposite direction, and walking to a world map hanging on the kitchen wall. As he approaches the map, and in overlap with Sofia's account for discarding northern Europe, Ettore produces a further ratification of Sofia's decision by acknowledging that this destination is being 'crossed off' (line 15).

Registering repetitions are typically uttered with a FALL contour and often include features of 'small' or 'downgraded' prosody, a recurrent one being low register (Figure 9). The type of nuclear contour can be transcribed as $\mathrm{H}+\mathrm{L} * \mathrm{~L} \%$ in ToBI notation.

As reported in prior literature, registering repetitions may or may not occasion a response. In (11), Sofia does not respond but continues the activity by providing an account for discarding northern Europe as a destination before moving on to other considerations (line 17). In other cases, registering repetitions receive minimal confirmation.

\section{O N C L U S I O N}

This study investigates the role of prosody in distinguishing the actions accomplished by other-repetition in Italian. It shows that that pitch contour is a central feature for the design and ascription of these actions, along with other prosodic features (pitch span and register) and visible behavior (head nods, eyebrow movements). The types of action examined in the study are reflected in the sequential development of the interaction and in the responses that are made relevant or afforded by the repetition (see Table 1). ${ }^{11}$

These results suggest that Italian speakers rely on a system of tunes. The system involves a limited set of recurrent melodies in oppositional relation to one another and associated with distinct action imports. A system also involves internal coherence in the way forms are functionally distributed. This means that, where there is 


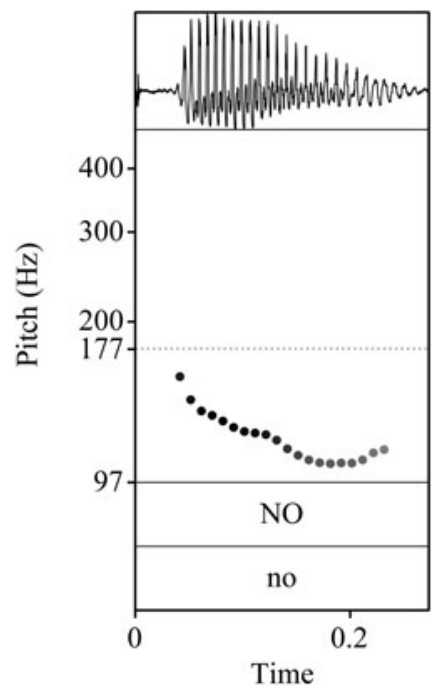

FIGURE 9. Waveform and pitch trace of Ettore's repetition (no 'no') in extract (11), line 10, produced with a FALL contour to register what Sofia has said.

overlap, the multiple functions of a given form are consistent with one another. The RISE-FALL contour, for instance, is used both to seek confirmation of and to display surprise at what has been said. While the two types of action have distinct imports, they are interactionally compatible with one another. As Persson (this issue) argues, response patterns including both confirmation and elaboration/affiliation suggest that an action of displaying surprise can be 'laminated onto' one of seeking confirmation. By contrast, seeking confirmation is not compatible with other actions such as seeking completion or questioning acceptability, which are typically designed with other pitch contours.

The coherence of the system extends outside the domain of other-repetition. As noted in the analysis, the RISE-FALL contour features in other practices for seeking confirmation of a candidate understanding or interpretation (Rossi 2015:271-73), and the RISE FROM HIGH contour can be used to prompt completion or continuation of a turn that has been left unfinished (see also Persson 2017, this issue).

Coherence is also found in the distribution of prosodic features other than pitch contour. The use of features of 'large' or 'upgraded' prosody for displaying surprise and of 'small' or 'downgraded' prosody for registering is consistent with other functions of these prosodic formats, for instance, in complaints, where the former works to pursue affiliation and sequence expansion while the latter works to close down the sequence (Ogden 2010).

This study adds to our understanding of the mechanics of action formation and ascription by documenting how prosody and other interactional resources 
TABLE 1. Summary of results.

\begin{tabular}{|c|c|c|c|c|}
\hline Function & Pitch contour & Other prosodic features & Visible behavior & Response \\
\hline \multicolumn{5}{|l|}{ INITIATING REPAIR } \\
\hline Seeking completion & $\begin{array}{l}\text { Rise from high } \\
\mathrm{L}+\mathrm{H}^{*}{ }_{i} \mathrm{H} \%\end{array}$ & & & Completion \\
\hline Seeking confirmation & $\begin{array}{l}\text { Rise-fall } \\
\mathrm{L}+\mathrm{H}^{*} \mathrm{~L} \%\end{array}$ & & Single head nod & Confirmation with stronger token (e.g. sì 'yes') \\
\hline \multicolumn{5}{|l|}{ BEYOND INITIATING REPAIR } \\
\hline Questioning acceptability: prechallenge & $\begin{array}{l}\text { Rise from low } \\
\mathrm{H}+\mathrm{L}^{*} \mathrm{LH} \%\end{array}$ & Low register & Eyebrows furrowed & Justification, modification, backdown \\
\hline Questioning acceptability: challenge & $\begin{array}{l}\text { Scooped rise-fall-rise } \\
\mathrm{L}^{*}+\mathrm{H} \mathrm{LH} \%\end{array}$ & & & \\
\hline Displaying surprise & $\begin{array}{l}\text { Rise-fall } \\
\mathrm{L}+\mathrm{H}^{*} \mathrm{~L} \%\end{array}$ & Wide span & Eyebrows raised & Confirmation+elaboration/affiliation \\
\hline \multicolumn{5}{|l|}{ OTHER THAN INITIATING REPAIR } \\
\hline Seeking confirmation prospectively & $\begin{array}{l}\text { Rise-fall-rise } \\
\mathrm{L}+\mathrm{H}^{*} \mathrm{LH} \%\end{array}$ & & & $\begin{array}{l}\text { Confirmation with weaker token or continuer } \\
\text { (e.g. } m m ~ h m)\end{array}$ \\
\hline Registering & $\begin{array}{l}\text { Fall } \\
\mathrm{H}+\mathrm{L} * \mathrm{~L} \%\end{array}$ & Low register & Turning away & None or minimal confirmation \\
\hline
\end{tabular}


contribute to this process across the domain of other-repetition. In doing so, the study also uncovers new action distinctions in the domain, including between pre- and outright challenges to what has been said, and between seeking confirmation retrospectively vs. prospectively.

A long-standing quest for intonational phonology is to determine exactly how and what meaning is delivered by intonation, a quest that remains elusive and contentious. As part of the larger project reported on in this special issue, the present study offers a way forward in this quest: by situating intonational contrasts in conversational structure, and by systematically examining the interplay of intonation with other interactional resources, both prosodic and otherwise.

\section{S U P P L E M E N T A R Y M A T E R I A L}

To view supplementary material for this article, please visit https://doi.org/10. $1017 /$ S0047404520000627.

\section{N O T E S}

*I am grateful to Rasmus Persson, Betty Couper-Kuhlen, Jack Sidnell, and Francisco Torreira for their comments and input at various stages of this study. I also benefited from conversations with Gene Lerner, Richard Ogden, Geoff Raymond, and Verónica Gonzáles Temer, and from the feedback I received from members of the LISO unit at the University of California, Santa Barbara on a presentation of this work. Any remaining errors and infelicities are my own. Finally, I wish to thank Susan Ehrlich for her patience and support during the writing of this article and the completion of the special issue. This research was supported by the Finnish Center of Excellence in Research on Intersubjectivity in Interaction directed by Marja-Leena Sorjonen (Academy of Finland grant \# 284595).

${ }^{1}$ http://gareth-walker.staff.shef.ac.uk/praat/visreps/

${ }^{2}$ As Sara explains in line 13, the 'challenge' is whether they will manage to get a sufficient amount of edible walnuts to make cookies.

${ }^{3}$ Sound clips are available as supplemental material at https://doi.org/10.1017/S0047404520000627.

${ }^{4}$ On the response-mobilizing function of gaze, see Stivers \& Rossano (2010).

${ }^{5}$ As noted in Rossi (2015:272), the peak of the rise is usually reached late in the stressed syllable. At the same time, the absence of a low target within the syllable makes a transcription as $\mathrm{L}+\mathrm{H}^{*}$ more appropriate than the previously suggested $\mathrm{L}^{*}+\mathrm{H}$ (see also Gili Fivela et al. 2015:169-72). This analysis is consistent with the fact that the contour is sometimes realized as an upstep to a high target.

${ }^{6}$ Spunto can also mean an initial idea or spark for something to be developed.

${ }^{7}$ When the stress is on the third-last syllable (or earlier), the pitch stays low until the last syllable.

${ }^{8}$ Another prosodic difference is that the peak of the RISE-FALL contour tends to be reached earlier in cases of displaying surprise than in cases of seeking confirmation (where it is usually found late in the stressed syllable).

${ }^{9}$ In one case, for example, the speaker repeats a request made to her as she in the process of fulfilling an earlier request by someone else; the speaker seeks confirmation of the second request with a prospective orientation to fulfilling it after she is done with the first request.

${ }^{10}$ The literal translation is provided to preserve the Italian word order; a more idiomatic translation would be 'no northern Europe'.

${ }^{11}$ Action labels such as seeking confirmation, questioning acceptability, and registering do not exhaustively describe the social-interactional significance of each repetition token in context; they 'thematize accountabilities' (Enfield \& Sidnell 2017) that emerge in the environment of other-repetition, and that are best understood in contrast to one another. 


\section{GIOVANNI ROSSI}

\section{R E F E R E N C E S}

Benjamin, Trevor M., \& Traci S. Walker (2013). Managing problems of acceptability through high risefall repetitions. Discourse Processes 50(2):107-38.

Bertinetto, Pier Marco, \& Michele Loporcaro (2005). The sound pattern of Standard Italian, as compared with the varieties spoken in Florence, Milan and Rome. Journal of the International Phonetic Association 35(2):131-51.

Boersma, Paul, \& David Weenink (2020). Praat: Doing phonetics by computer. University of Amsterdam. Online: http://www.praat.org/.

Bolden, Galina B. (2009). Beyond answering: Repeat-prefaced responses in conversation. Communication Monographs 76(2):121-43.

Chovil, Nicole (1991). Discourse-oriented facial displays in conversation. Research on Language \& Social Interaction 25(1-4):163-94.

Couper-Kuhlen, Elizabeth, \& Dagmar Barth-Weingarten (2011). A system for transcribing talk-in-interaction: GAT 2. English translation and adaptation of Margaret Selting et al.: Gesprächsanalytisches Transkriptionssystem 2. Gesprächsforschung: Online-Zeitschrift zur verbalen Interaktion 12:1-51.

Curl, Traci S. (2005). Practices in other-initiated repair resolution: The phonetic differentiation of 'repetitions'. Discourse Processes 39(1):1-43.

Darwin, Charles (1872). The expression of the emotions in man and animals. London: J. Murray.

Dingemanse, Mark; Joe Blythe; \& Tyko Dirksmeyer (2014). Formats for other-initiation of repair across languages: An exercise in pragmatic typology. Studies in Language 31(1):5-43.

, \& N. J. Enfield (2015). Other-initiated repair across languages: Towards a typology of conversational structures. Open Linguistics 1:96-118.

Drew, Paul (1997). 'Open' class repair initiators in response to sequential sources of troubles in conversation. Journal of Pragmatics 28(1):69-101.

Ekman, Paul; Wallace V. Friesen; \& Joseph C. Hager (2002). Facial action coding system: The manual. Salt Lake City, UT: Network Information Research Corporation.

Enfield, N. J., \& Jack Sidnell (2017). On the concept of action in the study of interaction. Discourse Studies 19(5):515-35.

Frota, Sónia, \& Pilar Prieto (eds.) (2015). Intonation in romance. New York: Oxford University Press.

Gardner, Rod (2001). When listeners talk: Response tokens and listener stance. Amsterdam: John Benjamins.

Gerhardt, Julie, \& Sandra Beyerle (1997). What if Socrates had been a woman? Contemporary Psychoanalysis 33(3):367-410.

Gili Fivela, Barbara; Cinzia Avesani; Marco Barone; Giuliano Bocci; Claudia Crocco; Mariapaola D'Imperio; Rosa Giordano; Giovanna Marotta; Michelina Savino; \& Patrizia Sorianello (2015). Intonational phonology of the regional varieties of Italian. In Sónia Frota \& Pilar Prieto (eds.), Intonation in romance, 140-97. New York: Oxford University Press.

Grice, Martine; Mariapaola D’Imperio; Michelina Savino; \& Cinzia Avesani (2005). Strategies for intonation labelling across varieties of Italian. In Sun-Ah Jun (ed.), Prosodic typology: The phonology of intonation and phrasing, 362-89. Oxford: Oxford University Press.

- \& Michelina Savino (2003). Map tasks in Italian: Asking questions about given, accessible and new information. Catalan Journal of Linguistics 2:153-80.

Hayashi, Makoto; Geoffrey Raymond; \& Jack Sidnell (2013). Conversational repair and human understanding: An introduction. In Makoto Hayashi, Geoffrey Raymond, \& Jack Sidnell (eds.), Conversational repair and human understanding, 1-40. Cambridge: Cambridge University Press.

Heath, Christian (1992). Gesture's discreet tasks: Multiple relevancies in visual conduct and in the contextualization of language. In Peter Auer \& Aldo di Luzio (eds.), The contextualization of language, 101-27. Amsterdam: John Benjamins.

Heritage, John (1984). A change-of-state token and aspects of its sequential placement. In J. Maxwell Atkinson \& John Heritage (eds.), Structures of social action: Studies in conversation analysis, 299-345. Cambridge: Cambridge University Press. 
Jefferson, Gail (1972). Side sequences. In David N. Sudnow (ed.), Studies in social interaction, 294 338. New York: The Free Press.

Kaukomaa, Timo; Anssi Peräkylä; \& Johanna Ruusuvuori (2014). Foreshadowing a problem: Turnopening frowns in conversation. Journal of Pragmatics 71:132-47.

Kelly, John, \& John Local (1989). Doing phonology: Observing, recording, interpreting. Manchester: Manchester University Press.

Krämer, Martin (2009). The phonology of Italian. Oxford: Oxford University Press.

Lewis, M. Paul; Gary F. Simons; \& Charles D. Fennig (eds.) (2014). Ethnologue: Languages of the world. 17th edn. Dallas, TX: SIL International. Online: http://www.ethnologue.com.

Mondada, Lorenza (2019). Conventions for multimodal transcription (v. 5.0.1). Online: https://www. lorenzamondada.net/multimodal-transcription.

Nolan, Francis (2006). Intonation. In Bas Aarts \& April McMahon (eds.), The handbook of English linguistics, 433-55. Malden, MA: Blackwell.

Ogden, Richard (2006). Phonetics and social action in agreements and disagreements. Journal of Pragmatics 38(10):1752-75.

(2010). Prosodic constructions in making complaints. In Dagmar Barth-Weingarten, Elisabeth Reber, \& Margret Selting (eds.), Prosody in interaction, 81-104. Amsterdam: John Benjamins.

Persson, Rasmus (2015). Registering and repair-initiating repeats in French talk-in-interaction. Discourse Studies 17(5):583-608.

(2017). Fill-in-the-blank questions in interaction: Incomplete utterances as a resource for doing inquiries. Research on Language \& Social Interaction 50(3):227-48.

Pillet-Shore, Danielle (2012). Greeting: Displaying stance through prosodic recipient design. Research on Language \& Social Interaction 45(4):375-98.

Robinson, Jeffrey D. (2013). Epistemics, action formation, and other-initiation of repair: The case of partial questioning repeats. In Makoto Hayashi, Geoffrey Raymond, \& Jack Sidnell (eds.), Conversational repair and human understanding, 261-92. Cambridge: Cambridge University Press.

Rossano, Federico (2010). Questioning and responding in Italian. Journal of Pragmatics 42(10):2756-71.

Rossi, Giovanni (2015). Other-initiated repair in Italian. Open Linguistics 1(1):256-82.

Russell, James A. (1997). Reading emotions from and into faces: Resurrecting a dimensional-contextual perspective. In James A. Russell \& JoséMiguel Fernández Dols (eds.), The psychology of facial expression, 295-320. Cambridge: Cambridge University Press.

Schegloff, Emanuel A. (1997). Practices and actions: Boundary cases of other-initiated repair. Discourse Processes 23(3):499-546.

- (2007). Sequence organization in interaction: A primer in conversation analysis, vol. 1. Cambridge: Cambridge University Press.

_ Gail Jefferson; \& Harvey Sacks (1977). The preference for self-correction in the organization of repair in conversation. Language 53(2):361-82.

Selting, Margret (1996). Prosody as an activity-type distinctive cue in conversation: The case of so-called 'astonished' questions in repair initiation. In Elizabeth Couper-Kuhlen \& Margret Selting (eds.), Prosody in conversation: Interactional studies, 231-70. Cambridge: Cambridge University Press.

Smith, Craig A., \& Heather S. Scott (1997). A componential approach to the meaning of facial expressions. In James A. Russell \& JoséMiguel Fernández Dols (eds.), The psychology of facial expression, 229-54. Cambridge: Cambridge University Press.

Sorjonen, Marja-Leena (1996). On repeats and responses in Finnish conversations. In Elinor Ochs, Emanuel A. Schegloff, \& Sandra A. Thompson (eds.), Interaction and grammar, 277-327. Cambridge: Cambridge University Press.

Stivers, Tanya (2008). Stance, alignment, and affiliation during storytelling: When nodding is a token of affiliation. Research on Language \& Social Interaction 41(1):31-57.

- \& Federico Rossano (2010). A scalar view of response relevance. Research on Language \& Social Interaction 43(1):49-56. 


\section{GIOVANNI ROSSI}

Svennevig, Jan (2008). Trying the easiest solution first in other-initiation of repair. Journal of Pragmatics 40(2):333-48.

Wilkinson, Sue, \& Celia Kitzinger (2006). Surprise as an interactional achievement: Reaction tokens in conversation. Social Psychology Quarterly 69(2):150-82.

Wu, Ruey-Jiuan Regina (2006). Initiating repair and beyond: The use of two repeat-formatted repair initiations in Mandarin conversation. Discourse Processes 41(1):67-109.

(Received 4 April 2020; revision received 16 May 2020; accepted 18 May 2020; final revision received 16 May 2020)

Address for correspondence: Giovanni Rossi

University of California, Los Angeles

Department of Sociology

375 Portola Plaza, 264 Haines Hall

Los Angeles, CA 90095-1551, USA

rossi@soc.ucla.edu 